\title{
Oscillatory combustion of propene during in situ mechanical activation of solid catalysts
}

\author{
Hannah Schreyer ${ }^{1, *}$ (D), Sarah Immohr ${ }^{2}$, and Ferdi Schüth ${ }^{1}$ \\ ${ }^{7}$ Max-Planck-Institut für Kohlenforschung, Mülheim an der Ruhr, Germany \\ ${ }^{2}$ Sasol Germany GmbH, Marl, Germany
}

Received: 30 January 2017

Accepted: 27 April 2017

Published online:

12 May 2017

(C) The Author(s) 2017. This article is an open access publication

\begin{abstract}
Mechanochemical activation of solids can lead to a strong increase in their activity as catalysts in heterogeneously catalyzed reactions. In the following, we report on the effects of solid catalyst activation during ball milling that lead to oscillatory behavior in $\mathrm{CO}$ and $\mathrm{CO}_{2}$ formation during propene oxidation. The oscillations arise under in situ ball milling conditions over chromium(III) oxide $\left(\mathrm{Cr}_{2} \mathrm{O}_{3}\right)$ and cerium(IV) oxide $\left(\mathrm{CeO}_{2}\right)$, respectively. The experiments were conducted under continuous gas flow at ambient pressure and temperature, using both a modified steel and a tungsten carbide milling vessel. Abrasion of particles from the steel milling vessel could be eliminated as the sole cause for the oscillations through substitution by a tungsten carbide milling vessel. The intensity and frequency of oscillations are shown to be dependent on the propene-to-oxygen ratio, the milling frequency, milling ball size and metal oxide used. Overall, $\mathrm{Cr}_{2} \mathrm{O}_{3}$ shows higher activity for oscillatory propene combustion under in situ mechanical activation than $\mathrm{CeO}_{2}$.
\end{abstract}

\section{Introduction}

Mechanochemical activation of solids has long been known to induce chemical changes, initiating or promoting chemical reactions. The first documented mechanochemical reaction dates back to the grinding of cinnabar around $400 \mathrm{BC}$ [1]. The term mechanochemistry and its position as a sub-topic in chemistry were introduced by Wilhelm Ostwald [2]. The field has shown promising pathways for quick, clean and solvent-free synthesis of various organic [3-5], metal-organic [4, 6] or inorganic substances
$[4,5,7,8]$. Recently, substantial efforts were invested in organocatalyzed reactions in a ball mill [9], as well as acid-catalyzed hydrolysis of (ligno-)cellulose [10, 11]. Additionally, mechanochemical activation of inorganic substances has been shown to enhance the rate of heterogeneously catalyzed reactions by creating defects and reduction of crystallite and particle size [12]. $\mathrm{CO}_{2}$ methanation was the first example in which the potential of in situ ball milling in heterogeneously catalyzed reactions was explored [13]. Recently, we showed that the in situ ball milling activation of a catalyst can lead to activity increases of a solid catalyst

Address correspondence to E-mail: hschreyer@mpi-muelheim.mpg.de 
by several orders of magnitude during $\mathrm{CO}$ oxidation [14]. Also unusual selectivities have been observed during in situ ball milling catalysis [15]. To describe the processes occurring during milling, several theories, such as the magma-plasma model [16] and the hotspot theory [16, 17], have been proposed. These assume high temperatures and pressures arising at the impact point between balls which in turn lead to continuing changes in the ball-milled materials. In addition, theoretical studies on the mechanism and kinetics of mechanochemical processes in comminuting devices show that short-time contact fusion of particles can play the key role in the occurring activation and chemical reactions $[18,19]$.

Heterogeneously catalyzed reactions are highly nonlinear, multilevel chemical systems, which are operated away from thermodynamic equilibrium. This can lead to the formation of temporal or spatiotemporal structures which can originate on various levels of a heterogeneous catalytic system [20, 21]. Oscillating reactions in heterogeneous catalysis at ambient pressure are known for several oxidation reactions such as the $\mathrm{CO}$ and methane oxidation over metal catalysts [20, 22]. Oscillations in propene oxidation to acrolein and $\mathrm{CO}_{2}$ have been observed using $\mathrm{CuO}$ catalysts at $278{ }^{\circ} \mathrm{C}$ [23], as well as in propane oxidation in the temperature range of $600-750{ }^{\circ} \mathrm{C}$ [24], which were attributed to change in oxidation state of the catalyst. In situ ball milling of a catalyst leads to continuous changes in the catalyst shape and structure, and continuous formation of local hot spots and / or high pressures due to impact of the balls or shearing at the walls of the milling vessel. This adds to the complexity of the heterogeneous catalytic system.

Herein, we report on the effects of solid catalyst activation during ball milling that lead to oscillatory behavior in $\mathrm{CO}$ and $\mathrm{CO}_{2}$ formation observed for the propene oxidation under in situ ball milling conditions at ambient temperature and pressure, using commercially available $\mathrm{Cr}_{2} \mathrm{O}_{3}$ and $\mathrm{CeO}_{2}$, and give insight into the phenomena arising from the changes in feed composition and milling conditions, respectively.

\section{Materials and methods}

\section{Materials}

Chromium(III) oxide $\left(\mathrm{Cr}_{2} \mathrm{O}_{3}\right)$, cerium(IV) oxide $\left(\mathrm{CeO}_{2}\right)$ and molybdenum(VI) oxide $\left(\mathrm{MoO}_{3}\right)$ were purchased from Sigma-Aldrich. Propene gas
(99.5 vol\%) was purchased from Messer and oxygen $(\geq 99.9995 \mathrm{~mol} \%)$ from Air Liquide and nitrogen ( $\geq 99.8 \mathrm{vol} \%$ ) from Prax Air. All reagents used in the experiments were of analytical grade and used without further purification.

\section{In situ ball milling reaction procedure}

All in situ ball milling experiments were performed in a RETSCH shaker mill MM400 with a modified milling vessels and milling balls (Fig. 1). The milling vessels were made of non-hardened stainless steel (1.4571) or tungsten carbide. The $25-\mathrm{ml}$ stainless steel milling vessels as well as the respective steel milling balls $(d=13.5 \mathrm{~mm})$ were self-made in the fine mechanics workshop using a lathe. The $25-\mathrm{ml}$ tungsten carbide milling vial and the respective milling balls $(d=10 \mathrm{~mm})$ were obtained from RETSCH and modified. All milling vials were equipped with a gas inlet and outlet via Swagelok fittings, with a cone at the gas outlet in order to prevent loss of catalyst by acting as a cyclone filter similar to the one previously described [14]. The milling vessels were additionally

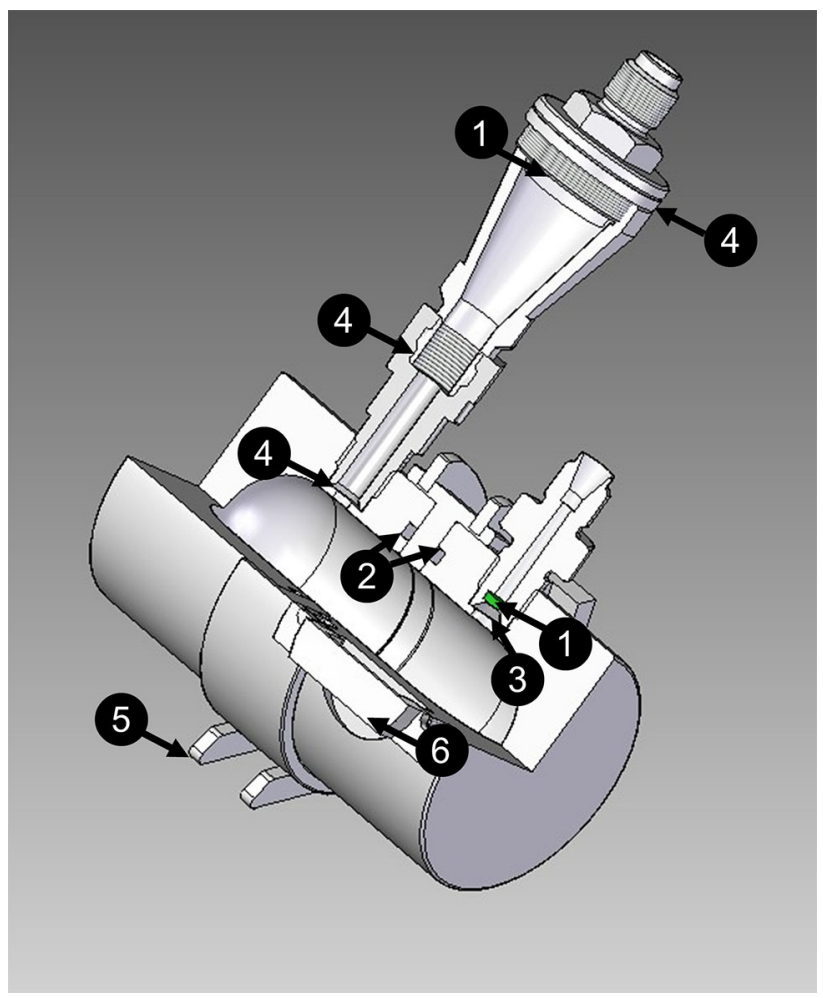

Figure 1 Quarter cross section of the modified steel milling vessel ( 1 frit, 2 rubber sealing, 3 brass sealing, 4 PEEK sealing, 5 clamp holding the milling vessel together, 6 fitting for temperature sensor). 
equipped with a wireless temperature sensor for measuring the vessel temperature or a thermocouple at the gas outlet for measuring the temperature inside the milling vessel.

After filling the milling capsule with catalyst material and milling balls, it was placed in the shaker mill and connected via Swagelok fittings to the gas flow system. Before starting the milling, the reaction gas flows were set separately to the requested value and then mixed via a T-mixer. Due to the fact that the photometer of the continuous IR spectrometer was calibrated to $\mathrm{CO}$ and $\mathrm{CO}_{2}$ values of $2.0 \mathrm{vol} \%$, the product gas flow after the mill was diluted with $700 \mathrm{ml} \mathrm{min}{ }^{-1}$ nitrogen in order to bring the concentrations to the calibrated range. The pressure at the beginning of the experiments was 1 bar. The gas flows were regulated with a gas flow meter and checked via a bubble meter before each experiment. Commercially available $\mathrm{Cr}_{2} \mathrm{O}_{3}$ (Sigma-Aldrich, powder $\geq 98 \%$ ), $\mathrm{CeO}_{2}$ (Sigma-Aldrich, nanopowder, 99.95\%) and $\mathrm{MoO}_{3}$ (Sigma-Aldrich, powder 99.97\%) were used without further purification. For the milling experiments, the respective vessel was filled with the catalyst (steel $1 \mathrm{~g}$; WC $2 \mathrm{~g}$ ) and balls (steel $2 \times d=13.5 \mathrm{~mm}$, non-hardened steel; WC $6 \times 10 \mathrm{~mm}, \mathrm{WC})$. The reactant gas mixture $\left(V_{\text {total }}\right.$ $=25 \mathrm{ml} \mathrm{min}{ }^{-1}$, varied $\mathrm{C}_{3} \mathrm{H}_{6}: \mathrm{O}_{2}$ ratios) was passed continuously through the milling vessel under milling at room temperature for $2-3 \mathrm{~h}$. The feed gas consisted of propene (99.5 vol\%, Messer) and oxygen ( $\geq 99.9995 \mathrm{~mol} \%$, Air Liquide). Products were analyzed using continuous IR spectroscopy (ABB EL 3000 Series with an URAS 26) or online-GC (Agilent HP 6890) equipped with a thermal conductivity detector (TCD), flame ionization detector (FID) and a PLOT-Q column. The propene conversions and CO and $\mathrm{CO}_{2}$ yields were calculated via the detected vol\% of $\mathrm{CO}$ and $\mathrm{CO}_{2}$ by the non-dispersive IR spectrometer (Supporting Information, S1). Online-GC measurements of the product gas stream showed no additional products. Therefore, all conversions and yields presented here are calculated based on the results of non-dispersive IR spectroscopy, due to the fact that it allows continuous sampling and therefore high resolution of the oscillations. Apparent propene conversions of over $100 \%$ result from pressure increase in the milling vessel, caused by temporary clogging of the gas outlet frit by catalyst powder due to the high volume increase upon combustion. The conversion of propene is calculated from the formation of $\mathrm{CO}$ and $\mathrm{CO}_{2}$ (Supporting Information, S1) and a propene inlet feed of $7.1 \mathrm{ml} \mathrm{min}^{-1}$, and therefore, a temporary clogging of the gas outlet frit leads to a higher propene amount available for combustion. Consequently, more $\mathrm{CO}$ and $\mathrm{CO}_{2}$ are formed during combustion, than would be possible for $7.1 \mathrm{ml} \mathrm{min}^{-1}$ propene, leading to apparent propene conversions over $100 \%$.

\section{Analysis}

Catalysts were characterized by powder X-ray diffraction (XRD) (STOE WinXPOW InstPar, $\mathrm{Cu}_{\mathrm{K} \alpha}$ radiation at $20 \mathrm{kV}$ and $5 \mathrm{~mA}$ ). Surface areas were determined by the BET method using NOVA 3200e (Quantachrome Instruments). Elemental analysis was performed externally by "Mikroanalytisches Laboratorium Kolbe" in Mülheim an der Ruhr, Germany.

\section{Results and discussion}

\section{Standard reaction milling conditions}

On starting the mill using the steel milling vessel at a milling frequency of $25 \mathrm{~Hz}$ and a propene-to-oxygen ratio of 1:2.5, immediate oscillatory $\mathrm{CO}$ and $\mathrm{CO}_{2}$ formation was observed using both $\mathrm{Cr}_{2} \mathrm{O}_{3}$ and $\mathrm{CeO}_{2}$. $\mathrm{Cr}_{2} \mathrm{O}_{3}$ showed more frequent oscillations, indicating higher activity toward the combustion of propene (Fig. 2). No reaction could be observed with catalyst (and balls) without milling. Furthermore, milling without catalyst using the steel milling vessel did not show any signs of $\mathrm{CO}$ and $\mathrm{CO}_{2}$ formation in the first $90 \mathrm{~min}$, confirming that the oscillations in the beginning did not arise from the steel mill or balls. Additionally, these experiments showed that while working in the explosive regime of propene in oxygen [25], the forces of milling alone did not induce the combustion of propene. Propene conversions of over $100 \%$ which occur for both materials after several minutes of milling result from pressure increase in the milling vessel arising from temporary clogging of the gas outlet frit by catalyst powder due to the high volume increase upon combustion. This phenomenon can be observed throughout the reported results.

Additionally, the in situ ball milling propene oxidation under the same conditions as described above was investigated using commercial $\mathrm{MoO}_{3}$. Milling in a steel milling vessel showed no oscillations over the 


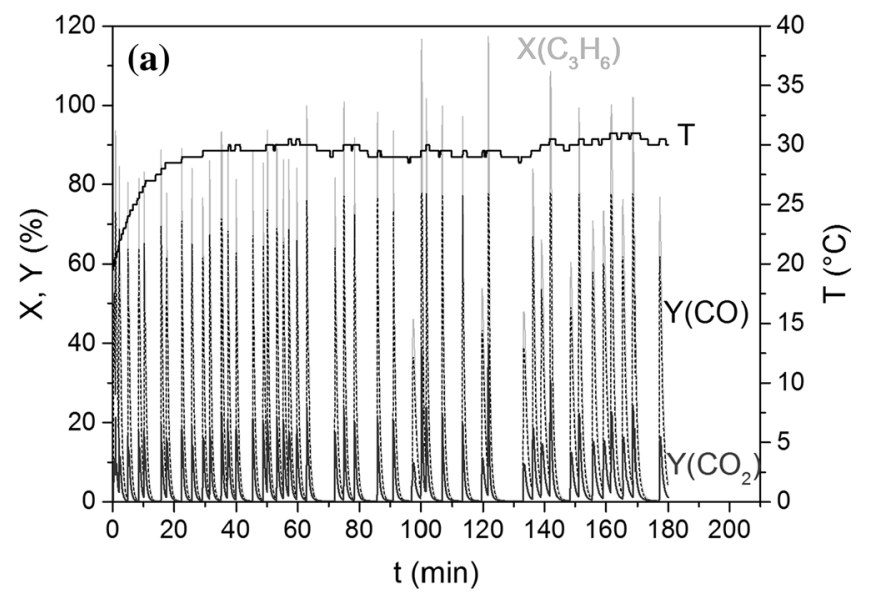

Figure 2 Conversion (\%) of propene (light gray) and yield (\%) of $\mathrm{CO}$ (dotted black) and $\mathrm{CO}_{2}$ (dark gray) and milling vessel temperature $\left({ }^{\circ} \mathrm{C}\right)$ versus reaction time $(\mathrm{min}) . \mathrm{Cr}_{2} \mathrm{O}_{3}(\mathbf{a})$ and $\mathrm{CeO}_{2}$

course of $3 \mathrm{~h}$ and only low conversions to $\mathrm{CO}_{2}$. The reaction resulted in a reduction of the catalyst to $\mathrm{MoO}_{2}$ (Supporting Information, Fig. S2.1). Therefore, in the case of $\mathrm{MoO}_{3}$, no catalytic but stoichiometric oxidation of propene was observed. This observation demonstrates that the oscillatory behavior of propene combustion is dependent on the material used and not attributed to the explosive gas conditions.

Using $\mathrm{Cr}_{2} \mathrm{O}_{3}$ and $\mathrm{CeO}_{2}$, the profile of a single oscillation showed a sharp peak in $\mathrm{CO}$ and $\mathrm{CO}_{2}$, followed by a shoulder, before declining to zero (Fig. 3). The shape of an oscillation as well as the ratio between $\mathrm{CO}$ and $\mathrm{CO}_{2}$ remained comparable over the

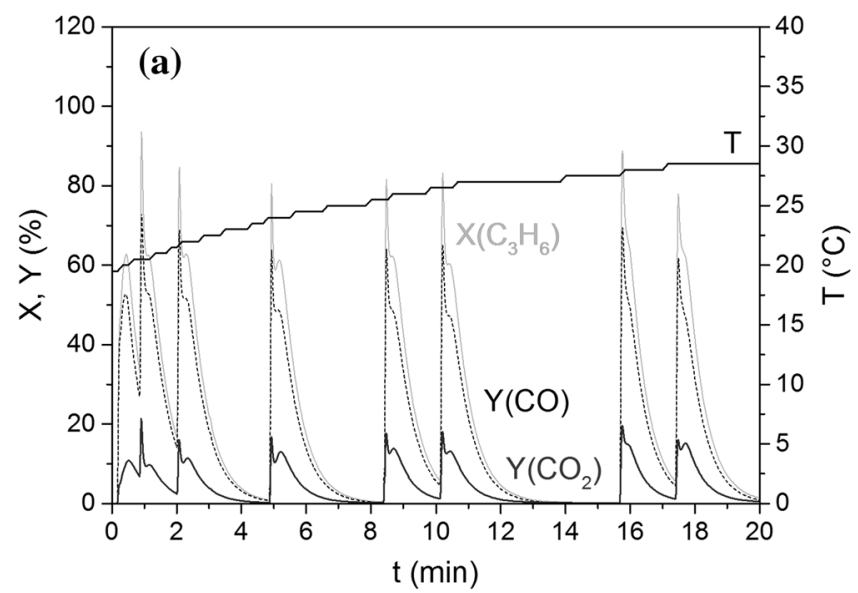

Figure 3 Conversion (\%) of propene (light gray) and yield (\%) of $\mathrm{CO}$ (dotted black) and $\mathrm{CO}_{2}$ (dark gray) and milling vessel temperature $\left({ }^{\circ} \mathrm{C}\right)$ versus reaction time $(\mathrm{min})$. Close-up of oscillation profile when using $\mathrm{Cr}_{2} \mathrm{O}_{3}(\mathbf{a})$ and $\mathrm{CeO}_{2}(\mathbf{b})$ as a catalyst under

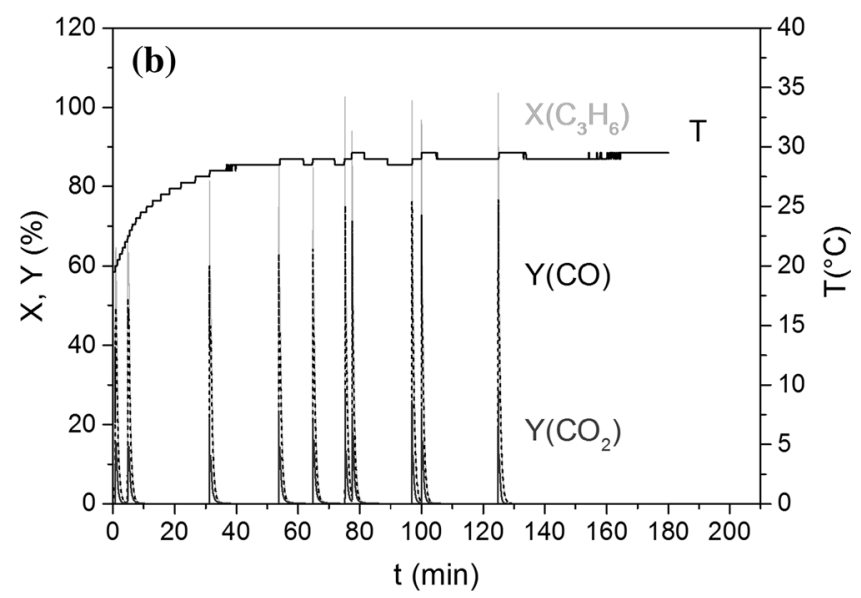

(b) under standard reaction conditions for propene oxidation in a steel milling vial $\left(\mathrm{C}_{3} \mathrm{H}_{6}: \mathrm{O}_{2}=1: 2.5\right.$; gas flow rate $=25$ $\mathrm{ml} \mathrm{min}-1 ; f=25 \mathrm{~Hz} ; \mathrm{N}_{2}$ product dilution $=700 \mathrm{ml} \mathrm{min}{ }^{-1}$ ).

course of the milling time. When using the steel milling vessel in the case of $\mathrm{CeO}_{2}$, the oscillations were all separated by regions of inactivity, ranging from seconds to several minutes (Fig. $2 \mathrm{~b}$ ). $\mathrm{Cr}_{2} \mathrm{O}_{3}$ on the other hand showed regions of overlapping oscillations and nearly no inactivity periods (Fig. 2a). After $60 \mathrm{~min}$, the shape of the oscillations changed, leading to a decrease and broadening of the peaks as well as a change in $\mathrm{CO}$ and $\mathrm{CO}_{2}$ ratio. The continuous oscillations led to regions of temporary high propene conversion with momentary high water production. This led to a moistening of the catalyst, resulting in clogging of the outlet frit and pressure increase in the

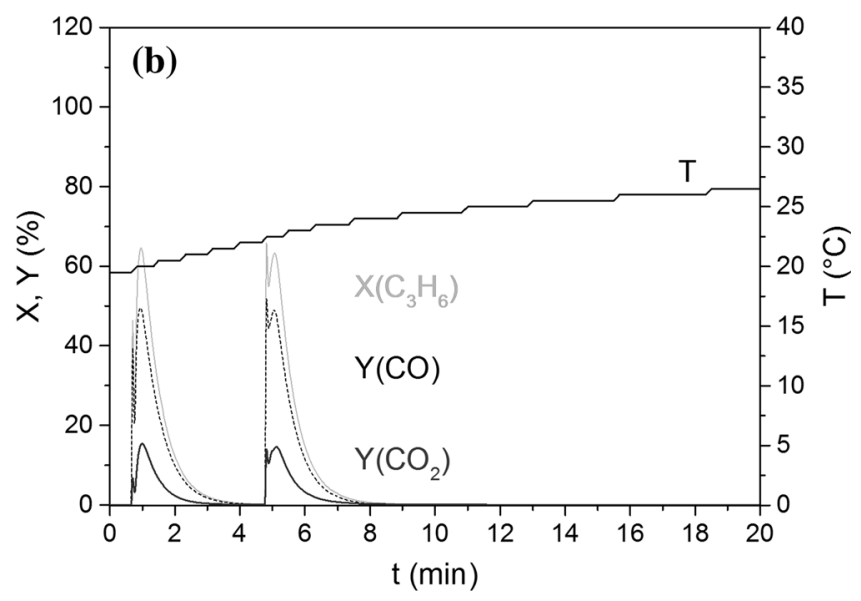

standard reaction conditions in a steel milling vial

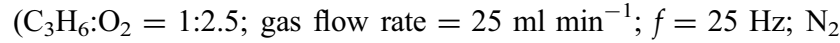

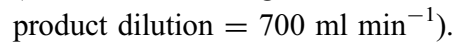


milling vessel. This phenomenon was very pronounced when using $\mathrm{Cr}_{2} \mathrm{O}_{3}$ as catalyst. Abrasion from the steel milling vessel and balls during the milling led to Taenite $(\mathrm{Fe}, \mathrm{Ni}), \mathrm{CeFeO}_{3}$ and $\mathrm{FeCr}_{2} \mathrm{O}_{4}$ formation, respectively (Fig. 4). These abrasion products could be ruled out as source for oscillations by substituting the steel milling vessel and balls by tungsten carbide. Using $\mathrm{Cr}_{2} \mathrm{O}_{3}$ and $\mathrm{CeO}_{2}$ in a tungsten carbide milling vessel with tungsten carbide milling balls $(6 \times 10 \mathrm{~mm})$ showed comparable oscillatory propene combustion behavior as observed in the steel milling vial (Supporting Information Fig. S2.2). Again $\mathrm{Cr}_{2} \mathrm{O}_{3}$ showed higher activity in comparison with $\mathrm{CeO}_{2}$.

In order to evaluate whether phase changes were responsible for the oscillatory reaction, both catalysts were analyzed via XRD before and after an oscillation. The powder diffraction pattern showed no signs of additional phases, indicating that oxidation or reduction of the catalyst bulk did not lead to the observed oscillations (Supporting Information S2.3). Since no in situ XRD could be performed during milling, the milling was always interrupted for measurements which might have changed the state of the catalyst. Additionally, elemental analysis of the catalyst was performed after $3 \mathrm{~h}$ milling at a propene-to-oxygen ratio of 1:2.5, giving an overall carbon content of below $1 \mathrm{wt} \%$, which demonstrates that there was insignificant carbon deposition during the reaction.

\section{Influence of reactant feed concentration}

To analyze the influence of the reactant feed concentration on the oscillations, the propene-to-oxygen ratio was varied. On further increase of oxygen content $\left(\mathrm{C}_{3} \mathrm{H}_{6}: \mathrm{O}_{2}=1: 5\right), \mathrm{CO}_{2}$ production dominated during the oscillations. Whereas in the case of $\mathrm{Cr}_{2} \mathrm{O}_{3}$ the oscillations appeared immediately and at high frequency (Fig. 5a), $\mathrm{CeO}_{2}$ exhibited groups of oscillations followed by regions of inactivity (Supporting Information, Fig. S2.4a). For $\mathrm{CeO}_{2}$ at equal oxygen-topropene ratio, nearly no activity and simply small spikes of $\mathrm{CO}$ and $\mathrm{CO}_{2}$ formation were observed (Supporting Information, Fig. S2.4b). Furthermore, a decrease of the oxygen content $\left(\mathrm{C}_{3} \mathrm{H}_{6}: \mathrm{O}_{2}=27: 23\right.$ and 1.5:1) led to a decline in the amplitude of the oscillation in the beginning of the reaction and at even higher propene excess $\left(\mathrm{C}_{3} \mathrm{H}_{6}: \mathrm{O}_{2}=2: 1\right)$ no activity for propene oxidation was observed (Supporting Information, Fig. S2.4c, d). Using $\mathrm{Cr}_{2} \mathrm{O}_{3}$ as catalyst at a propene-to-oxygen ratio of $1: 1$ and 27:23, the latter being outside of the explosion limits of propene in oxygen, showed small oscillations throughout the milling time, during which propene conversion of around $10 \%$ was achieved (Fig. 5b, c). Experiments with $\mathrm{Cr}_{2} \mathrm{O}_{3}$ at a propene-to-oxygen ratio of 1:1 were repeated using the tungsten carbide milling vial, showing differing conversions of propene throughout $3 \mathrm{~h}$ reaction time (see Fig. $5 \mathrm{~d}$ ). For total oxidation of propene to $\mathrm{CO}_{2}, 4.5$ equivalents of oxygen are necessary (Supporting Information, Eq. 2). If the reaction would proceed via a radical reaction, rather than via surface-catalyzed combustion, all available oxygen should react with propene. Therefore, in the case of a radical combustion, the lowest possible propene conversion at an oxygen-to-propene ratio of 1:1, even under the assumption of $100 \%$ total oxidation to $\mathrm{CO}_{2}$, should not lie below 22\%. Propene
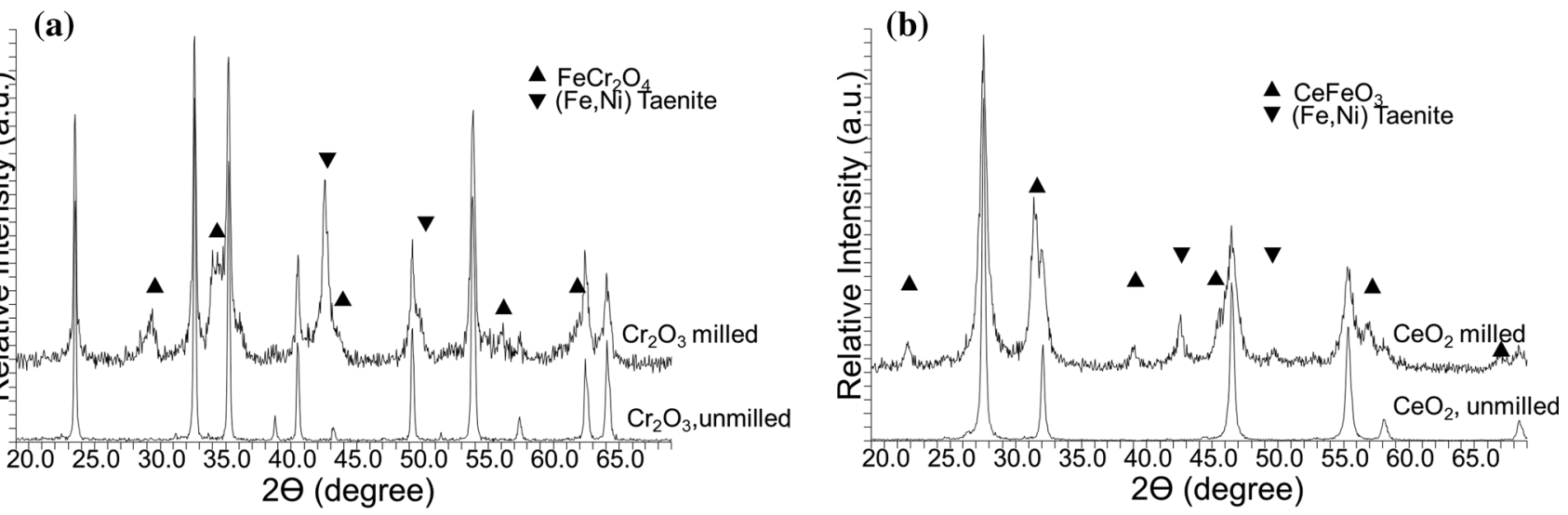

Figure 4 XRD patterns of $\mathrm{Cr}_{2} \mathrm{O}_{3}$ (a) and $\mathrm{CeO}_{2}$ (b) after 3-h milling under standard reaction conditions $\left(\mathrm{C}_{3} \mathrm{H}_{6}: \mathrm{O}_{2}=1: 2.5\right.$; gas flow rate $=25 \mathrm{ml} \mathrm{min} \operatorname{mon}^{-1} ; f=25 \mathrm{~Hz} ; \mathrm{N}_{2}$ product dilution $=700 \mathrm{ml} \mathrm{min}{ }^{-1}$ ). 

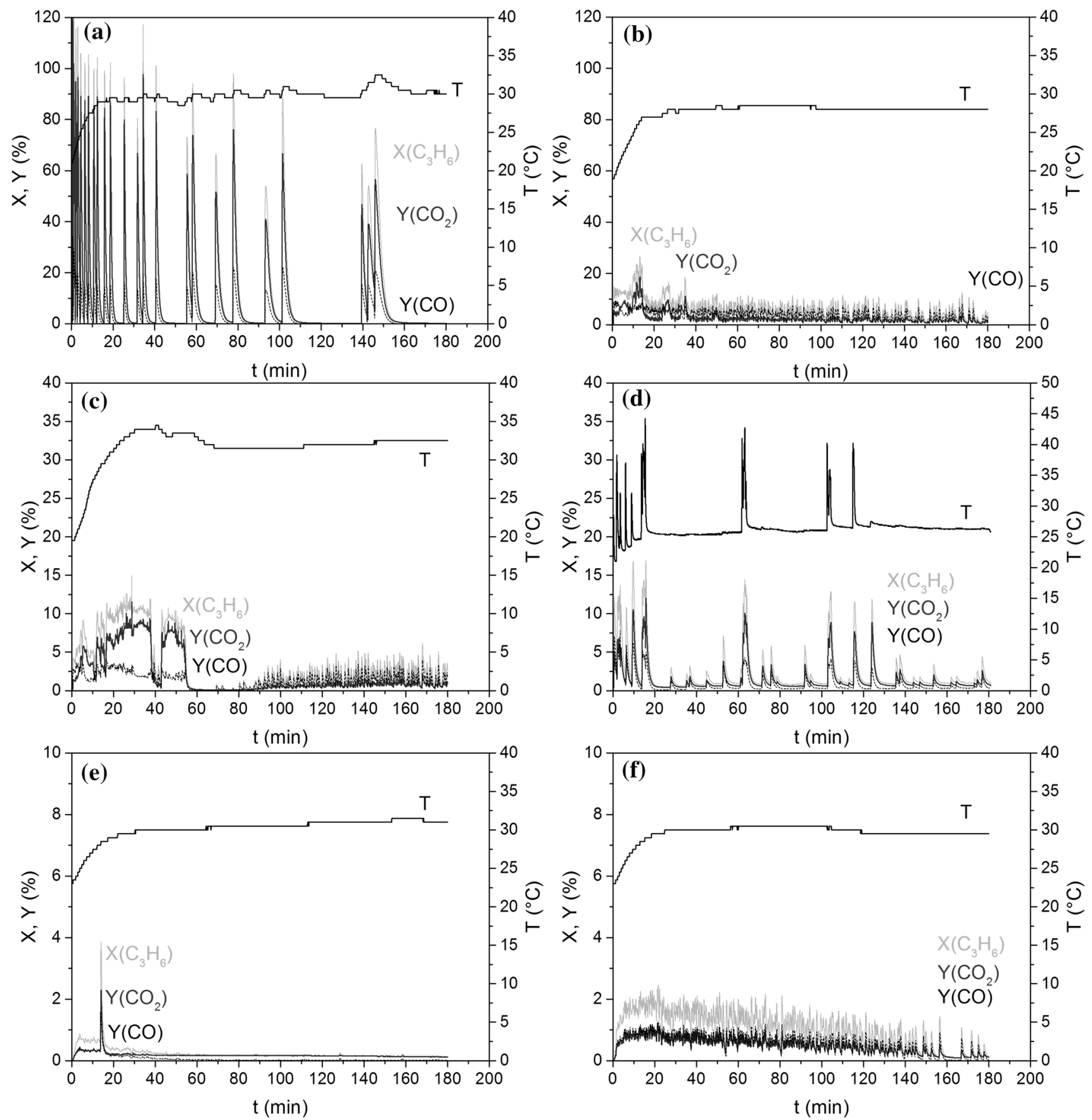

Figure 5 Conversion (\%) of propene (light gray) and yield (\%) of $\mathrm{CO}$ (dotted black) and $\mathrm{CO}_{2}$ (dark gray) and milling vessel temperature $\left({ }^{\circ} \mathrm{C}\right)$ versus reaction time (min). $\mathrm{Cr}_{2} \mathrm{O}_{3}$ under different propene-to-oxygen ratios (a 1:5, steel; b 1:1, steel; c 27:23, steel;

conversions in the range of $10 \%$ therefore suggest catalytic combustion. A further increase in propene concentration $\left(\mathrm{C}_{3} \mathrm{H}_{6}: \mathrm{O}_{2}=1.5: 1\right.$ and $\left.2: 1\right)$ did not lead to vanishing of the oscillations, but for a ratio of $2: 1$ their frequency increased while decreasing the conversion of propene to $1.5 \%$ after 3 -h milling (Fig. 5e,

d 1:1, WC; e 1.5:1, steel; f 2:1, steel) under milling conditions (gas flow rate $=25 \mathrm{ml} \mathrm{min} \min ^{-1} f=25 \mathrm{~Hz} ; \mathrm{N}_{2}$ product dilution $=700 \mathrm{ml} \mathrm{min}^{-1}$ ).

f). If the reaction were to proceed via a radical gasphase reaction rather than a catalytic pathway, no oscillations at all should be observable under these concentrations. Overall, the milling experiments at different propene-to-oxygen ratios show that the oscillatory reaction rate behavior for propene

\section{Springer}


combustion using $\mathrm{Cr}_{2} \mathrm{O}_{3}$ and $\mathrm{CeO}_{2}$ is maintained over a wide range of gas compositions, is induced by the in situ mechanical activation of the respective material and proceeds catalytically-although under some conditions the catalytic surface reaction may ignite a homogeneous gas-phase reaction.

In order to further examine the influence of the reactant feed composition on the catalyst, experiments were conducted in which the feed ratio was changed during milling from a propene-to-oxygen ratio of 1:2.5-1:5 and 2:1, respectively. Due to the overall lower activity of $\mathrm{CeO}_{2}$ with respect to $\mathrm{Cr}_{2} \mathrm{O}_{3}$, the former showed no substantial change in the oscillations when switching from a propene-to-oxygen ratio of 1:2.5 to higher oxygen excess $\left(\mathrm{C}_{3} \mathrm{H}_{6}: \mathrm{O}_{2}=1: 5\right)$ or propene excess $\left(\mathrm{C}_{3} \mathrm{H}_{6}: \mathrm{O}_{2}=2: 1\right)$ conditions, respectively (Supporting Information, Fig. S2.5). In the case of a propene-to-oxygen ratio of $1: 5$, widely separated oscillations producing mainly $\mathrm{CO}_{2}$ were observed. When switching between the propene-to-oxygen ratios, it took more than $10 \mathrm{~min}$ in each case to produce an oscillation. This reflects the previously stated lower activity of $\mathrm{CeO}_{2}$. When using $\mathrm{Cr}_{2} \mathrm{O}_{3}$, a change from high oxygen excess $\left(\mathrm{C}_{3} \mathrm{H}_{6}: \mathrm{O}_{2}=1: 5\right)$ to standard oscillating conditions $\left(\mathrm{C}_{3} \mathrm{H}_{6}: \mathrm{O}_{2}=1: 2.5\right)$ showed higher $\mathrm{CO}_{2}$ and lower $\mathrm{CO}$ production during the first oscillations, indicating higher oxygen uptake of the catalyst during oxygen richer conditions, without continuously inducing oscillations (Fig. 6a). In contrast, switching from a propene-rich reactant feed to standard oscillating conditions $\left(\mathrm{C}_{3} \mathrm{H}_{6}: \mathrm{O} 2=1: 2.5\right)$ resulted in a lower $\mathrm{CO}_{2}$ production during the first oscillations (Fig. 6b). Contrarily to experiments solely at high oxygen excess (Fig. 5a) or propene excess (Fig. 5f), switching between oxygen and propene ratios during milling did not lead to oscillations at the respective conditions. This shows that under given milling conditions a propene-to-oxygen ratio of 1:2.5 is most favorable to give rise to oscillations in propene combustion.

\section{Influence of milling parameters}

To further investigate the impact of in situ ball milling on the activation of the catalysts toward oscillatory behavior of propene oxidation, the milling frequency was stepwise reduced to $10 \mathrm{~Hz}$ while maintaining the oscillation-inducing reactant feed composition $\left(\mathrm{C}_{3} \mathrm{H}_{6}: \mathrm{O}_{2}=1: 2.5\right)$. As expected, on decrease of the milling frequency, the frequency of oscillations declined. $\mathrm{CeO}_{2}$ exhibited oscillatory reaction behavior down to a milling frequency of $20 \mathrm{~Hz}$ (Supporting Information, Fig. S2.6a). $\mathrm{Cr}_{2} \mathrm{O}_{3}$ showed activity down to a milling frequency of $10 \mathrm{~Hz}$, again attributed to its higher activity with respect to $\mathrm{CeO}_{2}$ (Supporting Information, Fig. S1.6b-d). To further illustrate the impact of milling on the catalytic reaction, blank experiments were performed in which (a) the catalyst was simply shaken without addition of milling balls under reaction gas flow, (b) reactant gas was passed through the mill, filled with catalyst and balls, but the mill was not operating and (c) pre-milled $\mathrm{CeO}_{2}$ and $\mathrm{Cr}_{2} \mathrm{O}_{3}$, respectively, were used as catalyst, with no milling during the reaction itself. In all cases, no

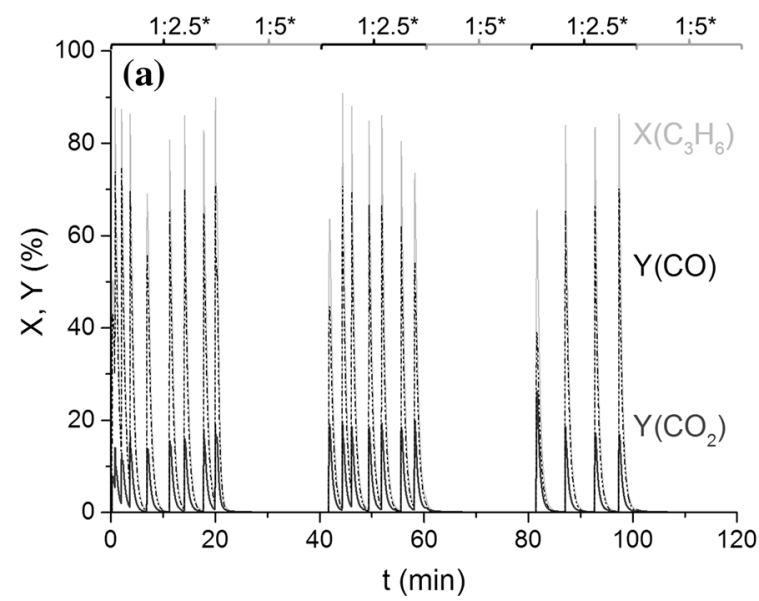

Figure 6 Variation in reactant gas flow ratios over $\mathrm{Cr}_{2} \mathrm{O}_{3}$ between $\mathrm{C}_{3} \mathrm{H}_{6}: \mathrm{O}_{2}=1: 2.5$ and $1: 5$ (a) and $2: 1$ (b) $\left(\mathrm{C}_{3} \mathrm{H}_{6}\right.$ flow rate $=7.1 \mathrm{ml} \mathrm{min}^{-1} ; f=25 \mathrm{~Hz}$ ). Conversion (\%) of propene

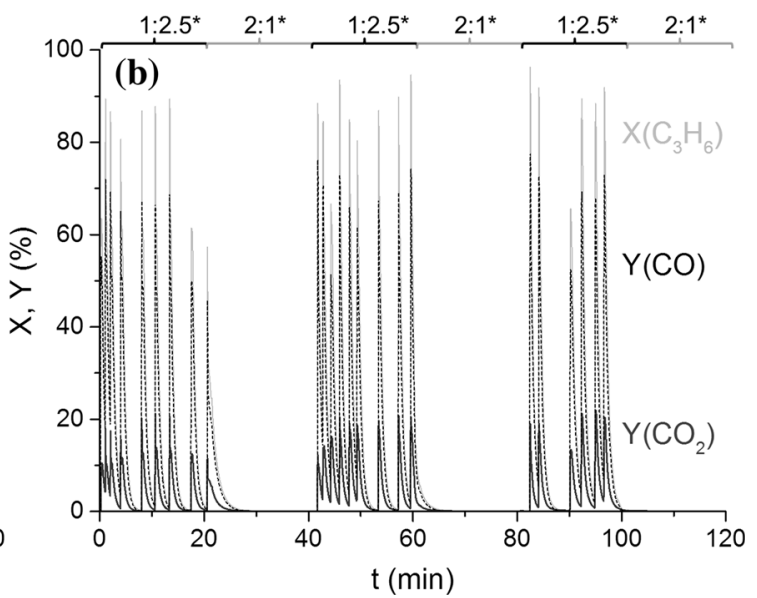

(light gray) and yield (\%) of $\mathrm{CO}$ (dotted black) and $\mathrm{CO}_{2}$ (dark gray) versus reaction time $(\mathrm{min})\left({ }^{*} \mathrm{C}_{3} \mathrm{H}_{6}: \mathrm{O}_{2}\right)$. 
propene conversion was observed. This clearly shows that milling of the catalyst is crucial for the reaction to proceed.

Finally, the impact of the milling ball size on the catalytic reaction was examined. On increasing the ball size to $d=15 \mathrm{~mm}$, the frequency of oscillations increased for both catalysts. Moreover, the shape of a single oscillation did change (Supporting Information, Fig. S2.7). These results reflect those obtained by milling at lower frequency. By increasing the mechanical force applied during the reaction, the activity toward propene combustion to $\mathrm{CO}$ and $\mathrm{CO}_{2}$ is increased.

\section{Comparison of the activity between $\mathrm{Cr}_{2} \mathrm{O}_{3}$ and $\mathrm{CeO}_{2}$}

Throughout the in situ milling experiments, $\mathrm{Cr}_{2} \mathrm{O}_{3}$ showed more frequent oscillations in $\mathrm{CO}$ and $\mathrm{CO}_{2}$ formation than $\mathrm{CeO}_{2}$, independent of the milling vessel used. At variation of the propene-to-oxygen ratio, $\mathrm{Cr}_{2} \mathrm{O}_{3}$ exhibited oscillations throughout 3-h milling, whereas at high propene-to-oxygen ratios, $\mathrm{CeO}_{2}$ only showed oscillations in the first $20 \mathrm{~min}$. These observations could be explained by the change in surface area observed for the materials after $3 \mathrm{~h}$ milling under reaction conditions. In the case of $\mathrm{Cr}_{2} \mathrm{O}_{3}$, the BET surface area increased during milling from 2.6 to $21.9 \mathrm{~m}^{2} \mathrm{~g}^{-1}$. Contrarily, the BET surface area of $\mathrm{CeO}_{2}$ decreased from 16.8 to $6.4 \mathrm{~m}^{2} \mathrm{~g}^{-1}$. In addition to the surface area, the forces applied during milling, which, among others, lead to stress and strain in the material, also play an important role in the oscillations. Upon decreasing the milling frequency, the activity of both materials toward propene combustion was decreased. However, $\mathrm{Cr}_{2} \mathrm{O}_{3}$ could be activated for oscillatory propene combustion at much lower milling frequencies than $\mathrm{CeO}_{2}$, again reflecting its higher activity.

\section{Radical versus catalytic combustion}

Several steps were undertaken to investigate the nature of the oscillations observed for propene combustion when activating materials under in situ ball milling conditions. When substituting $\mathrm{CeO}_{2}$ or $\mathrm{Cr}_{2} \mathrm{O}_{3}$ for $\mathrm{MoO}_{3}$ under standard milling reaction conditions $\left(\mathrm{C}_{3} \mathrm{H}_{6}: \mathrm{O}_{2}=1: 2.5 ;\right.$ gas flow rate $=25 \mathrm{ml} \mathrm{min}^{-1}$; $f=25 \mathrm{~Hz} ; \mathrm{N}_{2}$ product dilution $=700 \mathrm{ml} \mathrm{min}^{-1}$ ), no oscillations could be observed and $\mathrm{CO}_{2}$ formation could be traced back to the reduction of $\mathrm{MoO}_{3}-\mathrm{MoO}_{2}$. Additionally, milling without catalyst under standard milling reaction conditions showed no oscillations in $\mathrm{CO}$ and $\mathrm{CO}_{2}$ until there was enough material abraded from the steel milling vessel to induce these. Furthermore, reactions at a propene-to-oxygen ratio outside of the explosion limit also showed oscillatory behavior for both $\mathrm{CeO}_{2}$ and $\mathrm{Cr}_{2} \mathrm{O}_{3}$. Therefore, we can safely state that the oscillations in propene combustion observed when activating $\mathrm{Cr}_{2} \mathrm{O}_{3}$ and $\mathrm{CeO}_{2}$ under in situ ball milling conditions are induced catalytically. For unsupported $\mathrm{Cr}_{2} \mathrm{O}_{3}$, an easy oxidation of $\mathrm{Cr}^{3+}-\mathrm{Cr}^{6+}$ on the surface with the uptake of oxygen has been reported in several studies [26-28]. In the case of $\mathrm{CeO}_{2}$, its redox properties and high lability of lattice oxygen are also known to contribute to its catalytic activity in oxidation reactions [29]. The continuous milling of the catalyst during the reaction could lead to the accumulation of active surface sites which at certain saturation leads to sudden oxidation of propene. The change in oscillation profile during the course of the milling time shows that the change in surface structure, which occurs during milling, does indeed have an influence on the activity of the catalyst. This is especially visible in the oscillation profiles using $\mathrm{CeO}_{2}$. The oscillations in propene oxidation could be induced by oxidation and reduction processes on the surface of the catalysts, which are assisted by the milling. During milling of the catalyst under reaction conditions, it is constantly exposed to deterioration by impact, leading the system away from thermodynamic equilibrium by generating new defects and facets, resulting in a constant change in available adsorption sites on the catalyst. On changing of the reactant feed composition, a change in the surface of $\mathrm{Cr}_{2} \mathrm{O}_{3}$ under strongly oxidizing and reducing conditions was reflected by reproducible changes in $\mathrm{CO}$ and $\mathrm{CO}_{2}$ product ratios.

So far, the possibilities of in situ analysis during milling reactions are scarce, allowing to obtain only very little information on processes taking place during the milling, especially on the surface of the material being milled [30-32]. Ex situ XRD analysis showed no change in the oxidation state of the catalyst (Supporting Information, Fig. S2.3).

\section{Conclusion}

In summary, we have shown that in situ ball milling of $\mathrm{Cr}_{2} \mathrm{O}_{3}$ and $\mathrm{CeO}_{2}$ can lead to the activation of the respective solid, resulting in catalytically induced oscillations of propene oxidation to $\mathrm{CO}$ and $\mathrm{CO}_{2}$ under 
ambient temperature and pressure. We propose that the continuous changes in activity result from milling of the catalyst under reaction conditions which lead to continuous changes in the surface structure of the materials. This reaction is an exciting example of how mechanical activation of materials can influence the activity of solids toward heterogeneously catalyzed reactions. In the field of in situ mechanical activation of materials under reaction conditions, further research is necessary in order to investigate the mechanisms underlying the activation such as defect and hot spot formation, amorphization and the nature of the active surface species under milling conditions.

\section{Acknowledgements}

Open access funding provided by Max Planck Society. We thank Wolfgang Kersten and co-workers for modifications of the mills and the milling equipment.

\section{Compliance with ethical standards}

Conflict of interest The authors declare that they have no conflict of interest.

Electronic supplementary material: The online version of this article (doi:10.1007/s10853-017-1153-z) contains supplementary material, which is available to authorized users.

Open Access This article is distributed under the terms of the Creative Commons Attribution 4.0 International License (http://creativecommons.org/ licenses/by/4.0/), which permits unrestricted use, distribution, and reproduction in any medium, provided you give appropriate credit to the original author(s) and the source, provide a link to the Creative Commons license, and indicate if changes were made.

\section{References}

[1] Takacs L (2000) Quicksilver from cinnabar: the first documented mechanochemical reaction? JOM 52:12-13

[2] Ostwald W (1919) Handbuch der allgemeinen chemie. Akademische Verlagsgesellschaft, Leipzig

[3] Stolle A, Szuppa T, Leonhardt SES, Ondruschka B (2011) Ball milling in organic synthesis: solutions and challenges. Chem Soc Rev 4:2317-2329
[4] Friscic T, James SL, Boldyreva EV, Bolm C, Jones W, Mack J, Steed JW, Suslick KS (2015) Highlights from Faraday discussion 170: challenges and opportunities of modern mechanochemistry, Montreal, Canada, 2014. Chem Commun 51:6248-6256

[5] Boldyreva E (2013) Mechanochemistry of inorganic and organic systems: what is similar, what is different? Chem Soc Rev 42:7719

[6] Crawford D, Casaban J, Haydon R, Giri N, McNally T, James SL (2015) Synthesis by extrusion: continuous, largescale preparation of MOF's using little or no solvent. Chem Sci 6:1645-1649

[7] Subban CV, Ati M, Rousse G, Abakumov AM, Van Tendeloo G, Janot R, Tarascon J-M (2013) Preparation, structure, and electrochemistry of layered polyanionic hydroxysulfates: $\mathrm{LiMSO} 4 \mathrm{OH}(\mathrm{M}=\mathrm{Fe} \mathrm{Co}, \mathrm{Mn})$ electrodes for Li-Ion batteries. J Am Chem Soc 135:3653-3661

[8] Shao H, Felderhoff M, Schüth F (2011) Hydrogen storage properties of nanostructured $\mathrm{MgH}_{2} / \mathrm{TiH}_{2}$ composite prepared by ball milling under high hydrogen pressure. Int J Hydrogen Energy 36:10828-10833

[9] Hermann GN, Becker P, Bolm C (2015) Mechanochemical rhodium(III)-catalyzed $\mathrm{C}-\mathrm{H}$ bond functionalization of acetanilides under solventless conditions in a ball mill. Angew Chem Int Ed 54:7414-7417

[10] Meine N, Rinaldi R, Schüth F (2012) Solvent-free catalytic depolymerization of cellulose to water-soluble oligosaccharides. Chemsuschem 5:1449-1454

[11] Käldstrom M, Meine N, Fares C, Rinaldi R, Schüth F (2014) Fractionation of 'water-soluble lignocellulosé into $\mathrm{C}_{5} / \mathrm{C}_{6}$ sugars and sulfur-free lignins. Green Chem 16:2454-2462

[12] Buyanov RA, Molchanov VV, Boldyrev VV (2009) Mechanochemical activation as a tool of increasing catalytic activity. Catal Today 144:212-218

[13] Mori S, Xu WC, Ishidzuki T, Ogasawara N, Imai J, Kobayashi K (1996) Mechanochemical activation of catalysts for $\mathrm{CO}_{2}$ methanation. Appl Catal A 137:255-268

[14] Immohr S, Felderhoff M, Weidenthaler C, Schüth F (2013) An orders-of-magnitude increase in the rate of the solidcatalyzed $\mathrm{CO}$ oxidation by in-situ ball milling. Angew Chem Int Ed 52:12688-12691

[15] Eckert R, Felderhoff M, Schüth F (2017) Preferential carbon monoxide oxidation over copper-based catalysts under in situ ball milling. Angew Chem Int Ed 56:2445-2448

[16] James SL, Adams CJ, Bolm C et al (2012) Mechanochemistry: opportunities for new and cleaner synthesis. Chem Soc Rev 41:413-447

[17] Fox PG (1975) Mechanically initiated chemical reactions in solids. J Mater Sci 10:340-360. doi:10.1007/BF00540358 
[18] Urakaev FK, Boldyrev VV (2000) Mechanism and kinetics of mechanochemical processes in comminuting devices-1. Theory. Powder Technol 107:93-107

[19] Urakaev FK, Boldyrev VV (2000) Mechanism and kinetics of mechanochemical processes in comminuting devices 2 . Applications of the theory. Exp Powder Technol 107:197-206

[20] Slinko MM (2010) Oscillating reactions in heterogeneous catalysis: what new information can be obtained about reaction mechanisms? Catal Today 154:38-45

[21] Schüth F, Henry BE, Schmidt LD (1993) Oscillatory reactions in heterogeneous catalysis. Adv Catal 39:51-127

[22] Bychkov VY, Tyulenin YP, Slinko MM, Korchak VN (2009) Nonlinear behavior during methane and ethane oxidation over Ni. Co and Pd catal: Surf Sci 603:1680-1689

[23] Amariglio A, Benali O, Amariglio H (1989) Oscillating oxidation of propene on copper oxides. J Catal 118:164-174

[24] Kaichev VV, Gladky AY, Prosvirin IP, Saraev AA, Hävecker M, Knop-Gericke A, Schlögl R, Bukhtiyarov VI (2013) In situ XPS study of self-sustained oscillations in catalytic oxidation of propane over nickel. Surf Sci 609:113-118

[25] Profos P, Pfeifer T (1994) Handbuch der industriellen Messtechnik. R. Oldenbourg Verlag, München

[26] Weller SW, Voltz SE (1954) Surface chemistry of chromic oxide. J Am Chem Soc 76:4695-4701
[27] Dereń J, Haber J, Podgórecka A, Burzyk J (1963) Physicochemical and catalytic properties of the system chromium oxides-oxygen-water. J Catal 2:161-175

[28] Słoczyński J, Grzybowska B, Grabowski R, Kozłowska A, Wcisło K (1999) Oxygen adsorption and catalytic performance in oxidative dehydrogenation of isobutane on chromium oxide-based catalysts. Phys Chem Chem Phys $1: 333-339$

[29] Trovarelli A (1996) Catalytic properties of ceria and $\mathrm{CeO}_{2-}$ containing materials. Catal Rev Sci Eng 38:439-520

[30] Friscic T, Halasz I, Beldon PJ, Belenguer AM, Adams F, Kimber SAJ, Honkimaki V, Dinnebier RE (2013) Real-time and in situ monitoring of mechanochemical milling reactions. Nat Chem 5:66-73

[31] Gracin D, Strukil V, Friscic T, Halasz I, Uzarevic K (2014) Laboratory real-time and in situ monitoring of mechanochemical milling reactions by Raman Spectroscopy. Angew Chem Int Ed 53:6193-6197

[32] Batzdorf L, Fischer F, Wilke M, Wenzel KJ, Emmerling F (2015) Direct in situ investigation of milling reactions using combined X-ray diffraction and Raman Spectroscopy. Angew Chem Int Ed 54:1799-1802 